\title{
The Research on Influence Factors of entrepreneurial intention on Higher Vocational Students
}

\author{
Zhou Zucai ${ }^{1, a}$, Zhang $\mathrm{Xi}^{2, \mathrm{~b}^{*}}$ \\ ${ }^{1}$ Department of Computer and Information Engineer Hubei Communications Technical College \\ Wuhan, $\mathrm{P}, \mathrm{R}$ China \\ ${ }^{2}$ College of Management, Wuhan Institute of Technology, Wuhan, P,R.China \\ a453959786@qq.coml, bzhouzhangxi@foxmail.com \\ ${ }^{\star}$ Corresponding author
}

Keywords: Influence Factors, Entrepreneurship, Structural Equation Modal

\begin{abstract}
The objective of this article is influence factors of entrepreneurial intention on Higher Vocational Students. This paper takes three hierarchical indexes and designs the corresponding questionnaire to analysis the problem, and builds the Structural Equation Model based on the relationship of indexes. Finally we use AMOS software to validate and analysis data, give the final results.
\end{abstract}

\section{Introduction}

This paper investigates the influencing factors of Vocational College Students' entrepreneurial intention. There are many articles focus this problem. Belas investigates the relationship of social and economic factors of students' inclination to entrepreneurship[1]. Arranz studies entrepreneurial intention and obstacles of undergraduate students [2]. Ning considers the effect of satisfaction with entrepreneurial policy on entrepreneurial passion and entrepreneurial intention[3]. Chen explores the relationship between entrepreneurial learning, social network, entrepreneurial intention by the method of questionnaire with 244 entrepreneurs[4]. Ginanjar elaborates entrepreneurship education experience in Sharia Banking Program that using combination between theory and practice in one semester[5]. Wang not only considers the factor structures of the five-factor model of personality, the general self-efficacy scale, the entrepreneurial intention scale, and but also testes the mediating effect of self-efficacy on the relationship between personality traits and entrepreneurial intention among agricultural students[6]. Based on the available articles, this paper designs three hierarchical indexes.

\section{The construction of structural equation model}

\subsection{The index system}

Table 1 The index system of influencing factors of entrepreneurial intention.

\begin{tabular}{|c|c|c|}
\hline One level index & The second level index & The third level index \\
\hline \multirow{3}{*}{$\begin{array}{l}\text { Entrepreneurial } \\
\text { Intention } \\
\text { (A3/Q0) }\end{array}$} & $\begin{array}{l}\text { campus background } \\
\text { (A4/Q1) }\end{array}$ & $\begin{array}{c}\text { School support（A8/Q11） Entrepreneurial experience (A9/Q12) } \\
\text { Work experience (A10/Q13) Specialty (A11/Q14) }\end{array}$ \\
\hline & $\begin{array}{l}\text { family background } \\
\text { (A5/Q2) }\end{array}$ & Entrepreneurial help (A12/Q21) Family income (A13/Q22) \\
\hline & $\begin{array}{l}\text { personal quality } \\
\text { (A6/Q3) } \\
\text { social atmosphere } \\
\text { (A7/Q4) }\end{array}$ & $\begin{array}{c}\text { Professionalism (A14/Q31) Tenacity (A15/Q32) } \\
\text { Marketing ability (A16/Q33) personal charisma (A17/Q34) } \\
\text { national policy (A18/Q41) risk investment (A19/Q42) } \\
\text { Industry atmosphere (A20/Q43) }\end{array}$ \\
\hline
\end{tabular}

Note: The contents of $\mathrm{Ai}$ in brackets denote the corresponding title of the index in the questionnaire, and the contents of Qij denote the third level index under the second level index.

This paper takes the entrepreneurial as a primary level index. There are four second level indexes, namely school background, family background, personal quality and social atmosphere. According to the characteristics of each secondary level index, we select the third level index. Finally, these 
indexes and the hierarchical relationships of influencing factors of entrepreneurial intention on vocational college students are as shown in Table 1.

\subsection{The structural equation model}

In this paper, the questionnaire uses Likert 5-point scale, 20 questions are designed, including basic information questions, acceptance of single-choice questions.

Five latent variables of the model are the influencing factors of entrepreneurial intention, school background, family background, personal quality, and external atmosphere. According to the interaction and restriction among the five latent variables, the following hypothesis was established:

H1: "School background" has a positive impact on "Entrepreneurial intention";

H2: "Family background" has a positive impact on "Entrepreneurial intention";

H3: "Personal quality" has a positive impact on "Entrepreneurial intention";

H4: "Social atmosphere" has positive e impact on "Entrepreneurial intention";

H5: "School background" has a positive effect on "Personal quality";

H6: "Family background" has a positive effect on "Personal quality";

H7: "Social atmosphere" has positive e impact on "School background".

With the above hypothesis, a structural equation model (SEM) is constructed (as Fig 1).

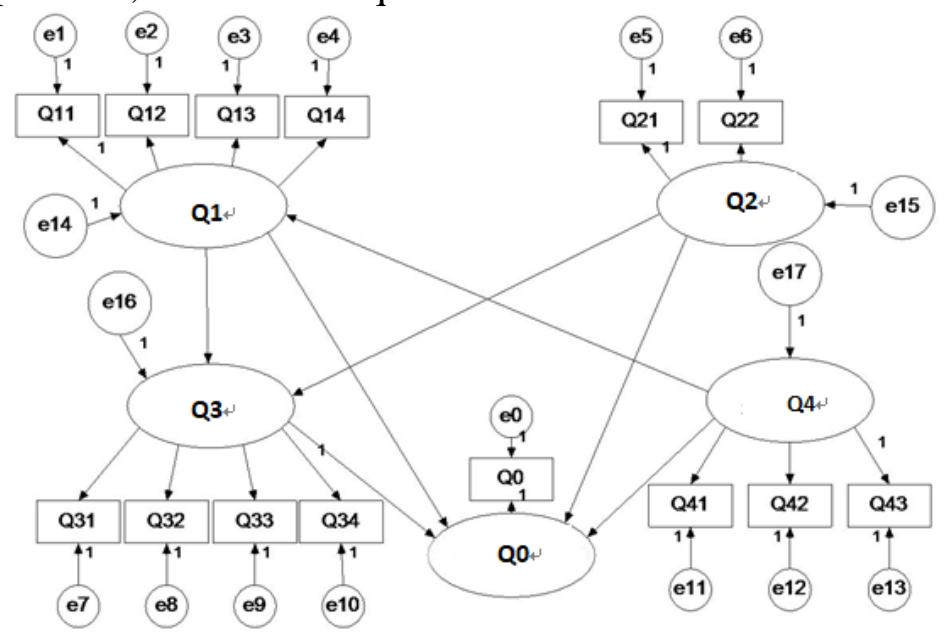

Fig 1 The structural equation model of influence factors of entrepreneurial intention.

\section{Model modification}

Table 2 The modified index table

\begin{tabular}{lll|rr}
\hline & & & M.I. & Par Change \\
\hline e15 & $<-->$ & e17 & 40.844 & .209 \\
e14 & $<-->$ & e15 & 19.275 & .107 \\
e4 & $<-->$ & e15 & 5.297 & .099 \\
e11 & $<-->$ & e15 & 14.898 & .117 \\
e11 & $<-->$ & e14 & 8.937 & .056 \\
e12 & $<-->$ & e16 & 6.156 & -.029 \\
e13 & $<-->$ & e12 & 4.546 & .078 \\
e6 & $<-->$ & e17 & 6.747 & .072 \\
e6 & $<-->$ & e12 & 7.243 & .094 \\
e5 & $<-->$ & e17 & 10.452 & .098 \\
e5 & $<-->$ & e14 & 7.165 & .061 \\
e3 & $<-->$ & e15 & 6.303 & .099 \\
e3 & $<-->$ & e13 & 4.780 & -.079 \\
e1 & $<-->$ & e4 & 6.218 & -.106 \\
e1 & $<-->$ & e3 & 4.244 & .080 \\
\hline
\end{tabular}


All the variances of the model are positive, and the standard deviation coefficients of each path are positive and the standardization coefficients are not more than 0.95 . The results show that violation estimation doesn't exist in all the paths, that is, the model is reasonable and feasible.

Absolute fitting index, relative fitting index and information index also accord with the standard. The construction reliability of the four potential variables is about 0.60 , indicating that the internal quality of the model is good. However, the model is deficient in goodness of fit and needs to be modified (as Table 2).

The relational routes are added based on the modified index table, and the optimal model is built (as Fig 2).

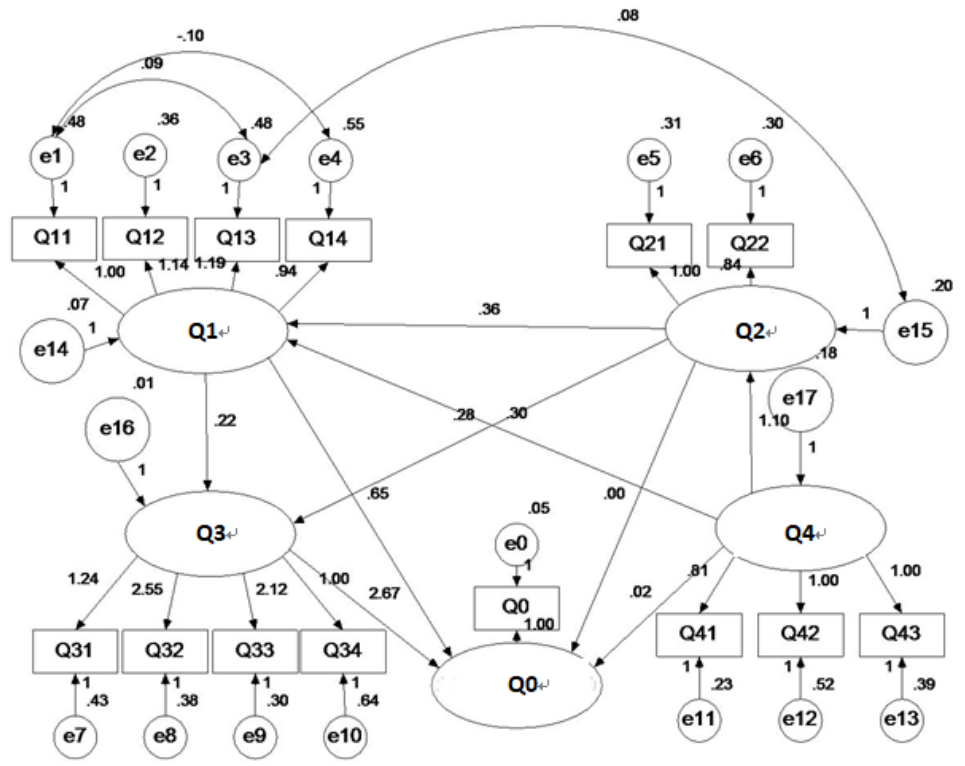

Figure 2 The optimal result

Table 3 Estimation of relationship coefficient

\begin{tabular}{|lll|r|}
\hline & & & Estimate \\
\hline Q2 & $<---$ & Q4 & .721 \\
Q1 & $<--$ & Q4 & .302 \\
Q1 & $<---$ & Q2 & .550 \\
Q3 & $<---$ & Q1 & .342 \\
Q3 & $<---$ & Q2 & .664 \\
Q0 & $<---$ & Q4 & .010 \\
Q0 & $<---$ & Q2 & .001 \\
Q0 & $<---$ & Q1 & .282 \\
Q0 & $<---$ & Q3 & .742 \\
Q11 & $<---$ & Q1 \\
Q12 & $<---$ & Q1 & .524 \\
Q13 & $<---$ & Q1 & .630 \\
Q21 & $<---$ & Q2 & .566 \\
Q22 & $<---$ & Q2 & .760 \\
Q0 & $<---$ & Q0 & .709 \\
Q34 & $<---$ & Q3 & .975 \\
Q33 & $<---$ & Q3 & .321 \\
Q43 & $<---$ & Q4 & .723 \\
Q42 & $<---$ & Q4 & .567 \\
Q41 & $<---$ & Q4 & .507 \\
Q31 & $<---$ & Q3 & .583 \\
Q32 & $<---$ & Q3 & .457 \\
Q14 & $<---$ & Q1 & .748 \\
\hline
\end{tabular}

The relationship between the variables with the optimal model is shown as table 3 . 
The influence coefficient of personal quality to entrepreneurial intention is biggest. It proves that personal quality of students is the most important factor on entrepreneurial intention. Secondly, the influence coefficient of school background on entrepreneurial intention is higher, indicating that school background is also very important for students' entrepreneurial intention. The weak positive correlations between potential variables are that school background and personal qualities, family background and school background, social atmosphere and school background. It shows that school education and family support are helpful to improve their personal qualities and the support of national policies plays a guiding role for education student in school. There is a strong positive correlation between the social atmosphere and family background. So the social atmosphere has obvious and positive influence on children's values of family culture.

\section{Summary}

This paper analyses the influence factors of entrepreneurial intention through kinds of levels, and get some interesting result. The personal quality of students and school background are very important factors for entrepreneurial intention. And the school plays an important role on culture of students. In the future we will study how to improve students' entrepreneurial intention through school education.

\section{Acknowledgement}

This study is partially sponsored by key project of Hubei Educational Science Planning (NO.2016GA073) and Teaching research project of Wuhan Institute of Technology (NO. X2014025).

\section{References}

[1] J. Belas , B. Gavurova, J. Schonfeld, K. Zvarikova, T Kacerauskas, Social and economic factors affecting the entrepreneurial intention of university students, Transformations in Business \& Economics, vol.16, pp. 220-239, 2017.

[2] N Arranz, M.F Arroyabe, JCFD Arroyabe, Entrepreneurial intention and obstacles of undergraduate students: the case of the universities of Andalusia. Studies in Higher Education, vol.1, pp.1-14,2018.

[3] D. P. Ning, B. S. Ge, Empirical Research on the Relationship among of Satisfaction of Entrepreneurial Policy, Entrepreneurial Passion and Entrepreneurial Intention, Journal of Huazhong University of Science and Technology (Social Science Edition) ,vol.3, pp.108-114 , 2017.

[4] H. S. Chen, X. Y. Chen, C. Lin, Entrepreneurial Learning and Entrepreneurial Intention: The Roles of Social Network and Entrepreneurial Self-efficacy, Review of Economy and Management , vol.5, pp.28-33,2017.

[5] A. Ginanjar, Entrepreneurship Education and Entrepreneurial Intention on Entrepreneurship Behavior: a Case Study, 1st Global Conference on Business, Management and Entreupreuneurship, pp.683-686,2016.

[6] J.H. Wang, C.C. Chang, S.N. Yao, C. Liang, The contribution of self-efficacy to the relationship between personality traits and entrepreneurial intention, Higher Education, vol.72 pp.1-16, 2016. 